\title{
LA LEGITIMACIÓN DE LA MÚSICA AFROCUBANA EN LA CRÍTICA PERIODÍSTICA DE ALEJO CARPENTIER
}

\author{
Viviana Gelado \\ Universidade Federal Fluminense
}

\begin{abstract}
RES U M O
No marco do questionamento da "alta" cultura e da arte como instituição, levado a cabo pelos movimentos de vanguarda na América Latina, este trabalho analisa os meios utilizados por Alejo Carpentier no exercício da crítica musical, desenvolvida em crônicas jornalísticas e orientada pelo propósito de legitimar a música afro-cubana através do questionamento da cultura musical institucionalizada no final da década de vinte em Cuba.
\end{abstract}

\section{PALAVRAS - CHAVE}

Afrocubanismo. Alejo Carpentier. Música.

El afrocubanismo, movimiento surgido en la década del veinte, articuló el primitivismo estético, como forma de cuestionamiento del arte como institución, mediante la refuncionalización de los materiales de la cultura afrocubana como componentes de un lenguaje nuevo; y el compromiso político, como forma de cuestionamiento de los imperativos económicos puestos por Estados Unidos sobre todo a partir de 1902. Y si bien "no descubrió la presencia de los negros en Cuba; [...] efectuó en cambio una revaloración radical en la posición que se les había asignado en la configuración de la cultura cubana". ${ }^{1}$ En ese marco, el movimiento contaba también, como los movimientos de vanguardia europeos, con la articulación de un proyecto estético y de un estudio antropológico sistemático, gracias a los trabajos realizados por Fernando Ortiz, desde la década anterior, sobre diversos aspectos de las culturas afrocubanas: rituales, lenguas, teatro, danza.

Por otro lado, y ante el imperativo de realizar un arte propio, frente a la antigua metrópoli colonial y frente a la amenaza contemporánea estadounidense, el afrocubanismo aparece como una forma de realización de un arte autóctono. En este sentido, el pronunciamiento de Carpentier en la polémica del meridiano intelectual, aunque moderado, es significativo de esta apuesta: “(...) es muy difícil que un artista joven piense seriamente en hacer arte deshumanizado. El deseo de crear un arte autóctono sojuzga todas las voluntades (...).” ${ }^{2}$

${ }^{1}$ GONZÁLEZ ECHEVARRÍA. Alejo Carpentier: el peregrino en su patria, p. 54.

${ }^{2}$ CARPENTIER. Carta abierta a Manuel Aznar sobre el meridiano intelectual de nuestra América, p. 148.

2008 - jan.-jun. - v. 17 - A le t R I A 
Coherente con esta apuesta, en iEcué-Yamba-O! -novela escrita en la cárcel en Cuba en 1927 y publicada en Madrid en 1933-, Carpentier optará por el uso extenso de vocablos afrocubanos; por la incorporación de las hablas rurales y urbanas populares, de invocaciones de la santería y de onomatopeyas comunes en la poesía afrocubana; por la articulación de una prosodia afrocubana; así como por la inclusión de ilustraciones y fotografías relativas a rituales ñáñigos y de un glosario en el que constan no solo vocablos afrocubanos sino aspectos de la cultura de esos sectores de la sociedad que eran conocidos hasta entonces apenas por "iniciados" y antropólogos. No obstante esto, la voz del narrador, al funcionar como comentarista de los episodios religiosos que aparecen en la novela, evidencia el mantenimiento de una separación conflictiva, en lo social y cultural.

Años más tarde, en La música afrocubana, Fernando Ortiz presentará como resuelto por la sobredeterminación de lo nacional (y mestizo), elementos que en la década del veinte aparecían en conflicto, particularmente en el ámbito de la música y la cultura, pero también en el de la literatura. En efecto, en un texto en el que en varios momentos resuenan cadencias de prosodia afrocubana, Ortiz afirma: Blanco, azúcar y guitarra; negro, tabaco y tambor. Hoy día, sincresis mulata, café con leche y bongó. Historia vivida en contradanza y tango, habanera y danzón, rumba y bembé, son que arrolla y son que enerva. ${ }^{3}$

Pero para el Alejo Carpentier de la década del veinte, la música afrocubana, notablemente a partir del estreno de La rebambaramba de Amadeo Roldán, en 1928, se transformará en la arena del debate sobre el rumbo que la vanguardia cubana debería tomar y sobre la necesidad de asumir, en ese momento y ante la dictadura de Machado, una posición política más amplia y definida. (Recordemos que el principal antecedente de la vanguardia cubana fue el Minorismo: referencia a un grupo de jóvenes, que surge en el campo cultural de la Isla luego del abortado Movimiento de Veteranos y Patriotas, manifestándose en 1923 contra el decreto firmado por el presidente Alfredo Zayas, que autorizaba la compra de un bien del patrimonio histórico: el Convento de Santa Clara.)

En el ámbito musical, como el propio Carpentier lo recordaría más tarde, hacia 1922 "la vida musical de La Habana (...) era nula (...) sólo interesaba la ópera (...) Estábamos totalmente invadidos por la melcocha”. ${ }^{4}$ Como toda vanguardia, el afrocubanismo se insurgió contra el gusto musical institucionalizado y, pedagógicamente, asumió la tarea de "orientar al público hacia géneros distintos creando en él una conciencia nueva de la diversidad de su folklore y de las posibilidades sinfónicas que ese folklore ofrecía". ${ }^{5} \mathrm{O}$, como lo expresaría en una crónica enviada desde París, al festejar el éxito de la soprano Rita Montaner con las composiciones de Simons y Grenet: “iAl fin se escriben canciones criollas sin poemas de Amado Nervo!”. 6

Pedagógicamente también, el debate en los medios se vio acompañado desde 1926 por la realización de los "Conciertos de música nueva", organizados por Carpentier y

\footnotetext{
${ }^{3}$ ORTIZ. Estudiemos la música afrocubana, p. 163.

${ }^{4}$ CARPENTIER. Panorama de la música en Cuba. La música contemporánea, p. 166.

${ }^{5}$ CARPENTIER. Panorama de la música en Cuba. La música contemporánea, p. 167.

${ }^{6}$ CARPENTIER. Las nuevas ofensivas del cubanismo, p. 254.
} 
Roldán, en cuyo marco se escucharon, por primera vez en la Isla, composiciones de Stravinsky, Satie y otros contemporáneos.

Empeñado en la misma empresa, antes del estreno de La rebambaramba, el también minorista Francisco Ichaso protestaba, en un artículo en la Revista de avance (de la que Carpentier sería también por poco tiempo uno de "los cinco" editores):

El folk-lore, que en nuestro país es tan pródigo, tan sustancioso, como lo ha demostrado musicalmente un joven compositor, Amadeo Roldán, (...) ha sido desfigurado (...) por mor de ese afán italianizante. Se ha pretendido encauzar la vena amplia, cálida y palpitante de nuestro folk-lore en los cangilones angostos de una modalidad donizettiana o pucciniana (...), rompiendo de ese modo con su encanto agreste, con su primitivo frescor. (...)

iIrritabilidad ante el prejuicio! He ahí lo que falta en nuestro medio, no ya en el orden musical, sino en todos los órdenes: en el estético, en el ético, en el político (...). ${ }^{7}$

En efecto, Carpentier había asumido el papel de "abogado defensor" de los ritmos afrocubanos ya en 1922 en París, en el Club du Faubourg. El relato de este "juicio público" aparece en una crónica periodística, en cuyo título resuenan el del ballet de Stravinski y, consecuentemente, el de la novela futura de Carpentier: "La consagración de nuestros ritmos", publicada en Carteles, el 10 de abril de 1922. El relato, escrito con un júbilo no disimulado, refiere los detalles de la presentación y debate, que contó con dirección musical de Moisés Simons, números de canto y danza y una explicación del "abogado defensor" al público parisiense sobre "orígenes, características y virtudes de la música cubana. Genealogía de la rumba. Nacimiento y desarrollo del son. Vida y milagros de Moisés Simons...". Recuerda también los orígenes populares de otros géneros musicales exitosos en París en ese momento (el tango y el jazz) y señala el ritmo como característica esencial de la música cubana. La crónica se cierra con la noticia de la presentación en concierto, con la Orquesta Sinfónica de París dirigida por Nicolás Slonimsky, de las Tres danzas cubanas de García Caturla, al final de un programa en el que también había piezas de Béla Bartók.

En sus críticas musicales publicadas en Social y Carteles, y en su obra de ficción contemporánea (la novela iEcué-Yamba-O!), en los libretos para ballets (El milagro de Anaquillé, Historia de lunas, Yamba-O), así como en las nueve canciones de Poèmes des Antillas, Carpentier ataca, pues, el exclusivismo con el que es tratada la ópera en el ámbito musical habanero y aboga por el reconocimiento de la música afrocubana, adoptando como referencia metonímica de esa disputa, en diversos momentos, un instrumento de percusión afrocubano: el bongó.

Así, Carpentier aprovecha el escándalo producido por La rebambaramba, en general, por su utilización de un modelo de composición de raíz popular (aportado a la Isla por los esclavos procedentes de África durante el período colonial, pero también enriquecido por las contribuciones de los ex-esclavos haitianos y jamaiquinos, traídos a Cuba ya en el período republicano como mano de obra barata, sobre todo para la época del boom azucarero consecuente con la Primera Guerra Mundial) y, en especial, por la

\footnotetext{
${ }^{7}$ ICHASO. El prejuicio de nuestra evolución musical, p. 162 y 175.

${ }^{8}$ CARPENTIER. La consagración de nuestros ritmos, p. 213.
} 
improvisación de tambores final, para la cual Roldán tuvo que desarrollar nuevas normas de transcripción gráfica. ${ }^{9}$

Carpentier pasa entonces a usar metonímicamente el bongó como instrumentosímbolo de legitimación de la música afrocubana, a la que atribuye el carácter de realización del primitivismo vanguardista internacional en el ámbito cultural local, y de resistencia a las imposiciones económicas norteamericanas en el ámbito político local. Así, en iEcué-Yamba-O!, el narrador exclamará: “iEl bongó, antídoto de Wall-Street!”. ${ }^{10}$

Por otro lado, la disputa no estará exenta de vocablos caros a los manifiestos futuristas: la Obertura sobre temas cubanos de Roldán no interesa solo por "la rara calidad de su 'materia musical', sino principalmente [por] la sana orientación estética" que revela. ${ }^{11}$

De la misma manera, y como lo hicieron las vanguardias constructivas, en crónica que comenta nuevamente la Obertura sobre temas cubanos y también los Tres pequeños poemas de Roldán, ${ }^{12}$ Carpentier inicia la constitución de una tradición en el gesto que caracteriza a la nueva orientación musical, reconociendo en las Danzas de Ignacio Cervantes el antecedente más acabado de esfuerzo de actualización de la producción local en relación con la internacional. Por otro lado, ya en el segmento dedicado a los Tres pequeños poemas, el cronista apunta como méritos de la pieza "la estilización de los elementos populares" hábil y "justa” de "Pregón”, el segundo "poema"; al tiempo que, al comentar el tercero, "Fiesta negra", el discurso del crítico se llena de aliteraciones, sinestesias percutivas e imágenes de movimiento:

"Fiesta negra" nos pega, nos golpea implacablemente (...) Ráfagas de acordes, acotados por formidables golpes de tam-tam, son arrancados al metal. Atravesamos un momento de violencia; un cúmulo de recias anarquías armónicas se entroniza en la orquesta. Y, sin tardanza, un agrio motivo de rumba se enuncia; el ritmo, seco, obsesionante, todopoderoso, comienza a sacudir frenéticamente los instrumentos; el tema es zarandeado, triturado; se alza de pronto para volver a caer; si se corporeizara lo veríamos saltar de los metales a las maderas como una gruesa pelota roja.

Y continúa,

La percusión se inquieta, se multiplica; los percutores típicos se unen a la batería tradicional (...); distintos ritmos se desintegran (...) y se combinan en una polirritmia furiosa. La orquesta clama a vos en cuello su áspero motivo; la formidable rumba adquiere proporciones épicas. ${ }^{13}$

Marcada por un discurso bélico en más de un momento, esta crónica-manifiesto también ensaya una defensa de lo afrocubano frente a los ataques hechos a esta orientación pretextando razones de nacionalismo. La defensa del "abogado" del Club du Fauborg, en este aspecto, se articula en dos líneas: una que podríamos considerar

${ }^{9}$ ORTIZ. Estudiemos la música afrocubana, p. 167.

${ }^{10}$ CARPENTIER. iEcué-Yamba-O!, p. 125-126.

${ }^{11}$ CARPENTIER. Una obra sinfónica cubana, p. 28 (subr. VG).

${ }^{12}$ CARPENTIER. Amadeo Roldán y la música vernácula, p. 55-61.

${ }^{13}$ CARPENTIER. Amadeo Roldán y la música vernácula, p. 58-59. 
interna, local, y otra que se sirve de las experiencias contemporáneas internacionales. En el primer caso, el cronista se pregunta si los más populares ritmos criollos (bolero, guaracha, danza), de filiación europea, son más nacionales que la clave y la rumba; puesto que el son, de acuerdo con Sánchez de Fuentes, se habría originado "entre los campesinos de (...) Oriente". ${ }^{14}$

En el segundo caso, el cronista recuerda que, con Milhaud, Satie, Stravinski y otros, la música europea incorporó, sin pruritos nacionalistas, "aires de machichas brasileras (...) y de síncopas de rag times". ${ }^{15}$

A propósito del compositor ruso, el cronista aprovecha el estreno de Las bodas para extraer consideraciones sobre las posibilidades que el neoprimitivismo de la vanguardia europea abre en el campo musical y, específicamente, sobre los elementos que contribuirían al desarrollo de un lenguaje musical nuevo en la música cubana. El análisis formal de la obra en pauta revela, según el crítico, notables coincidencias compositivas con el son cubano. Así, la definición y separación de los elementos ritmo y melodía; el tratamiento contrapuntístico y diatónico del componente vocal; la intensidad lírica expresada a través del ritmo; el carácter polirrítmico de la composición; los motivos en 6 por 8; la función atribuida a la "percusión articulada" o, en palabras de Stravinski, la "parte golpeada" (de pianos, tambores, triángulo, platillos, pandereta, cajas, timpani y xilófonos en Las bodas; y de tres y guitarra en el son) dan, a ambos, Las bodas y el son criollo, el carácter de sinfonías polirrítmicas. ${ }^{16}$ Bastaría, en consecuencia, a los compositores cubanos el estudio riguroso de la técnica de los neoprimitivistas europeos y su posterior utilización sobre materiales autóctonos: sugerencia semejante a la que contemporáneamente también daba Villa-Lobos. ${ }^{17}$

Un año después del estreno de La rebambaramba en La Habana y París (1928), al presentar el "misterio coreográfico afrocubano" El milagro de Anaquillé (música de Roldán, libreto de Carpentier, decorado y trajes de José Hurtado de Mendoza), el crítico musical de la Revista de Avance, Francisco Ichaso, anota las diferencias entre esta pieza y la anterior. En efecto, si en la anterior predominaba lo rítmico, "sobre lo musical y lo plástico", la actual significa un retorno a la musicalidad emotiva y la "hibridez de composición" que permite la incorporación de elementos guajiros y jazzísticos en contraste con los afrocubanos. ${ }^{18}$

En efecto, después del auge de la polémica, con el autoexilio de Carpentier y la aceptación de las composiciones de Roldán y García Caturla en París, el afrocubanismo podía permitirse una apertura hacia una heterogeneidad mayor e incorporar en sus realizaciones elementos diversos, locales (guajiros) y externos (el jazz de los negros norteamericanos); una vez que había llevado a cabo la actualización de la música

\footnotetext{
${ }^{14}$ CARPENTIER. Amadeo Roldán y la música vernácula, p. 60.

${ }^{15}$ CARPENTIER. Amadeo Roldán y la música vernácula, p. 61.

${ }^{16}$ CARPENTIER. Stravinski, Las bodas y Papá Montero, p. 84-90.

${ }^{17}$ CARPENTIER. Una fuerza musical de América: Héctor Villa-Lobos, p. 187-193.

${ }^{18}$ ICHASO. El milagro de Anaquillé, p. 314-315.
} 
sinfónica cubana y que había conquistado un reconocimiento en el marco de la vanguardia internacional, gracias a la valorización que había operado de la aportación africana a la cultura nacional.

\section{A}

\section{RESUMEN}

En el marco del cuestionamiento de la "alta" cultura y del arte como institución, llevado a cabo por los movimientos de vanguardia en América Latina, este trabajo analiza los medios utilizados por Alejo Carpentier en el ejercicio de la crítica musical, desarrollada en crónicas periodísticas y orientada por el propósito de legitimar la música afrocubana a través del cuestionamiento de la cultura musical institucionalizada hacia fines de la década del veinte en Cuba.

PALABRAS - CLAVE

Afrocubanismo. Alejo Carpentier. Música.

\section{BIBLIOGRAFÍA}

AGÜERO y BARRERAS, Gaspar. El aporte africano a la música popular cubana. Estudios Afrocubanos. La Habana, v. V, p. 113-128, 1945-1946.

BARTÓK, Béla. Escritos sobre música popular. 6. ed. México: Siglo XXI, 2006. 272p.

CAIRO, Ana. La revolución del 30 en la narrativa y el testimonio cubanos. La Habana, Letras Cubanas, 1993. 431p.

CARPENTIER, Alejo. Amadeo Roldán y la música vernácula [Carteles, 13.II.1927]. In: . Obras completas. México: Siglo XXI, 1986. p. 55-61. v. IX.

CARPENTIER, Alejo. Carta abierta a Manuel Aznar sobre el meridiano intelectual de Nuestra América. [Diario de la Marina, 12, IX, 1927], Casa de las Américas. La Habana, n. 84, p. 147-150. 1974.

CARPENTIER, Alejo. La consagración de nuestros ritmos" [Carteles, 10.IV.1922]. In: . Obras completas. 2. ed. México. Siglo XXI, 1998. p. 211-216. v. 8.

CARPENTIER, Alejo. iÉcue-Yamba-Ó!, novela afrocubana. Buenos Aires: Vallares, 1983. 231p.

CARPENTIER, Alejo. Una fuerza musical de América: Héctor Villa-Lobos [Social, v. 14, n. 8, ago.1929] In: . Obras completas. México: Siglo XXI, 1986. p. 187-193. v. IX.

CARPENTIER, Alejo. La música en Cuba. In: . Obras completas. México: Siglo XXI, 1987. p. 205-492. v. XII.

CARPENTIER, Alejo. Una obra sinfónica cubana [Social, v. 11, n. 2, feb. 1926]. In: Obras completas. México: Siglo XXI, 1986. p. 28-32. v. IX.

CARPENTIER, Alejo. Obras completas. 6. ed. México: Siglo XXI, 2002. v. I. 313p. (Contiene: Écue-Yamba-Ó, La rebambaramba, Cinco poemas afrocubanos, Historia de lunas, Manita en el suelo, El milagro de Anaquillé, Correspondencia con García Caturla) 
CARPENTIER, Alejo. Las nuevas ofensivas del cubanismo. [Carteles, 15.XII.1929]. In: . Obras completas. 2. ed. México: Siglo XXI, 1998. p. 249-254. v. 8.

CARPENTIER, Alejo Panorama de la música en Cuba. La música contemporánea. [Revista musical chilena. Santiago de Chile, 1947]. In: : Obras completas. México: Siglo XXI, 1987. p. 161-174. v. XII.

CARPENTIER, Alejo. Stravinski, Las bodas y Papá Montero [Social, v. 12, n. 12, dic. de 1927]. In: : Obras completas. México: Siglo XXI, 1986. p. 84-90. v. IX.

GONZÁLEZ ECHEVARRÍA, Roberto. Alejo Carpentier: el peregrino en su patria. México: UNAM, 1993. 414p.

ICHASO, Francisco. El milagro de Anaquillé, 1929. Revista de Avance, La Habana, n. 39, 15, X, p. 314-315, 1929.

ICHASO, Francisco. El prejuicio en nuestra evolución musical, 1927. Revista de Avance, La Habana, n. 7, 15, VI, p. 161-162 e 175, 1927.

ICHASO, Francisco. La rebambaramba, 1928. Revista de Avance, La Habana, n. 26, 15, IX, p. 244-246, 1928.

ORTIZ, Fernando. Estudiemos la música afrocubana. Estudios Afrocubanos, La Habana, v. V, p. 7-18, 1945-1946.

ORTIZ, Fernando. La música afrocubana. Madrid: Júcar, 1974. 339p.

QUINTERO-RIVERA, Mareia. A cor e o som da nação: a idéia de mestiçagem na crítica musical do Caribe hispânico e do Brasil (1928-1948). São Paulo: Annablume/ Fapesp, 2000. 218p. 